\title{
VCSEL-Based DWDM PON With 4 BIT/S/HZ Spectral Efficiency Using Carrierless Amplitude Phase Modulation
}

Rodes Lopez, Roberto; Wieckowski, Marcin; Pham, Tien Thang; Jensen, Jesper Bevensee; Tafur Monroy, Idelfonso

\section{Published in:}

Proceedings of the European Conference on Optical Communication (ECOC) 2011

Publication date:

2011

Document Version

Publisher's PDF, also known as Version of record

Link back to DTU Orbit

Citation (APA):

Rodes Lopez, R., Wieckowski, M., Pham, T. T., Jensen, J. B., \& Tafur Monroy, I. (2011). VCSEL-Based DWDM PON With 4 BIT/S/HZ Spectral Efficiency Using Carrierless Amplitude Phase Modulation. In Proceedings of the European Conference on Optical Communication (ECOC) 2011 (pp. Mo.2.C.2). Optical Society of America. http://www.ecoc2011.org/

\section{General rights}

Copyright and moral rights for the publications made accessible in the public portal are retained by the authors and/or other copyright owners and it is a condition of accessing publications that users recognise and abide by the legal requirements associated with these rights.

- Users may download and print one copy of any publication from the public portal for the purpose of private study or research.

- You may not further distribute the material or use it for any profit-making activity or commercial gain

- You may freely distribute the URL identifying the publication in the public portal 


\title{
VCSEL-based DWDM PON with 4 bit/s/Hz Spectral Efficiency using Carrierless Amplitude Phase Modulation
}

\author{
Roberto Rodes, Marcin Wieckowski, Thang Tien Pham, Jesper Bevensee Jensen and Idelfonso Tafur Monroy \\ DTU Fotonik, Department of Photonics Engineering, Technical University of Denmark, Dk-2800 Kgs. Lyngby, Denmark. \\ rrlo@fotonik.dtu.dk
}

\begin{abstract}
We experimental demonstrate successful performance of VCSEL-based WDM link supporting advanced 16-level carrierless amplitude/phase modulation up to $1.25 \mathrm{Gbps}$, over $26 \mathrm{~km}$ SSMF with spectral efficiency of $4 \mathrm{bit} / \mathrm{s} / \mathrm{Hz}$ for application in high capacity PONs. OCIS codes: (060.2330) Fiber optics communications; (060.4080) Modulation.
\end{abstract}

\section{Introduction}

The increasing bit-rate per user demand in access networks requires systems that can support higher capacity. In order to satisfy the capacity needs, access networks are moving from classic spectral inefficient non-return to zero time-division multiplexing (NRZ-TDM), to wavelength-division multiplexing (WDM) and more advanced modulation formats. Moreover, the complexity raise has to be kept to the minimum in order make the system feasible for access networks. Different techniques have been used for advanced modulation, such as discrete multitone (DMT) [1], and carrierless amplitude/phase CAP [2]. For high-speed transmission, the overall CAP architecture has been demonstrated to be less complex and with better performance than DMT architecture [3]. Moreover, highspeed multilevel CAP implementation has been demonstrated by using analog filters [4].

Vertical cavity surface emitting lasers (VCSELs) are especially attractive for access networks, due to their low manufacturing cost and low power consumption. Compared to edge-emitting lasers, VCSELs have inferior performance in terms of linewidth, chirp, stability or linearity. Therefore it is very important to understand and evaluate the feasibility of employing VCSELs for applications requiring higher laser performance.

Our paper proposes and experimentally demonstrates a VCSEL-based WDM system with CAP modulation for access networks. The experiment successfully demodulates 4 channels $100 \mathrm{GHz}$ spacing after $26 \mathrm{~km}$ of SSMF. Each VCSEL is directly modulated at $1.25 \mathrm{Gbps}$ in a $312.5 \mathrm{MHz}$ bandwidth, corresponding to a spectral efficiency of 4 $\mathrm{bit} / \mathrm{s} / \mathrm{Hz}$. To our knowledge, this is the first demonstration of a VCSEL based WDM CAP system. This shows the potential for using VCSELs as light sources in DWDM PON, supporting spectral efficient modulation formats and operating over a modest baseband bandwidth favoring low complexity electronics.

\section{CAP Modulation for Access Networks and short-range links}

Carrierless amplitude/phase modulation (CAP) is a multilevel and multidimensional modulation technique proposed by Bell Labs [5]. In contrast with quadrature amplitude modulation (QAM), CAP does not use a sinusoidal carrier to generate two orthogonal components. CAP uses two orthogonal signature waveforms to modulate the data in two dimensions. At the receiver, two filters reconstruct the signal from each component. CAP is especially attractive for access networks and short-range links as it uses low complexity electronics, and more channels allocation due to the high spectral efficiency.

In this experiment, we have used four levels encoding for each dimension generating the so-called CAP-16. Previous publication demonstrated 8 levels encoding CAP-64 [6], 3 orthogonal components 3D-CAP[7] and working with bit-rate up to $40 \mathrm{Gbps}$ [4].

\section{Experimental Setup}

Figure 1 shows the setup used in the proof of principle experiment. A $500 \mathrm{MHz}$-bandwidth, $1.25 \mathrm{Gsa} / \mathrm{s}$ Arbitrary Waveform Generator (ArbWG) is used to generate the CAP-16 signal at $1.25 \mathrm{Gbps}$. ArbWG features limits our CAP-16 signal up to $1.25 \mathrm{Gbps}$ with an upsampling 4 to ensure no aliasing products. The 2 outputs of the ArbWG are split in 2 and delayed to emulate $4 \times 1.25$ Gbps uncorrelated CAP signals. Each uncorrelated CAP signal directly modulates a $1550 \mathrm{~nm}$ VCSEL. The output power of each VCSEL is approximately $-1 \mathrm{dBm}$. At the transmitter side, the four wavelengths or channels, are multiplexed with a passive optical power combiner; while at the receiver side, wavelength demultiplexing is done with an arrayed waveguide grating (AWG). The power combiner has conversion loss of $7.5 \mathrm{~dB}$. The AWG has an insertion loss of $1.5 \mathrm{~dB}$. The VCSELs are wavelength-tuned by tuning the bias current in order to fit the $100 \mathrm{GHz}$-spacing grid of the AWG. Optionally, 2 AWGs with the same grid can be used for multiplexing and demultiplexing wavelengths, resulting in $6 \mathrm{~dB}$ additional power margin. The system was 
evaluated after $26 \mathrm{~km}$ transmission of standard single mode fiber (SSMF), with total fiber attenuation of $7.8 \mathrm{~dB}$. A variable optical attenuator is placed after the fiber for bit error rate (BER) measurements. Each channel is detected by a PIN photodiode and stored in a digital storage scope (DSO) for offline demodulation. The demodulation is done in Matlab by filtering the signal with 2 receiving CAP filters to reconstruct each orthogonal component.

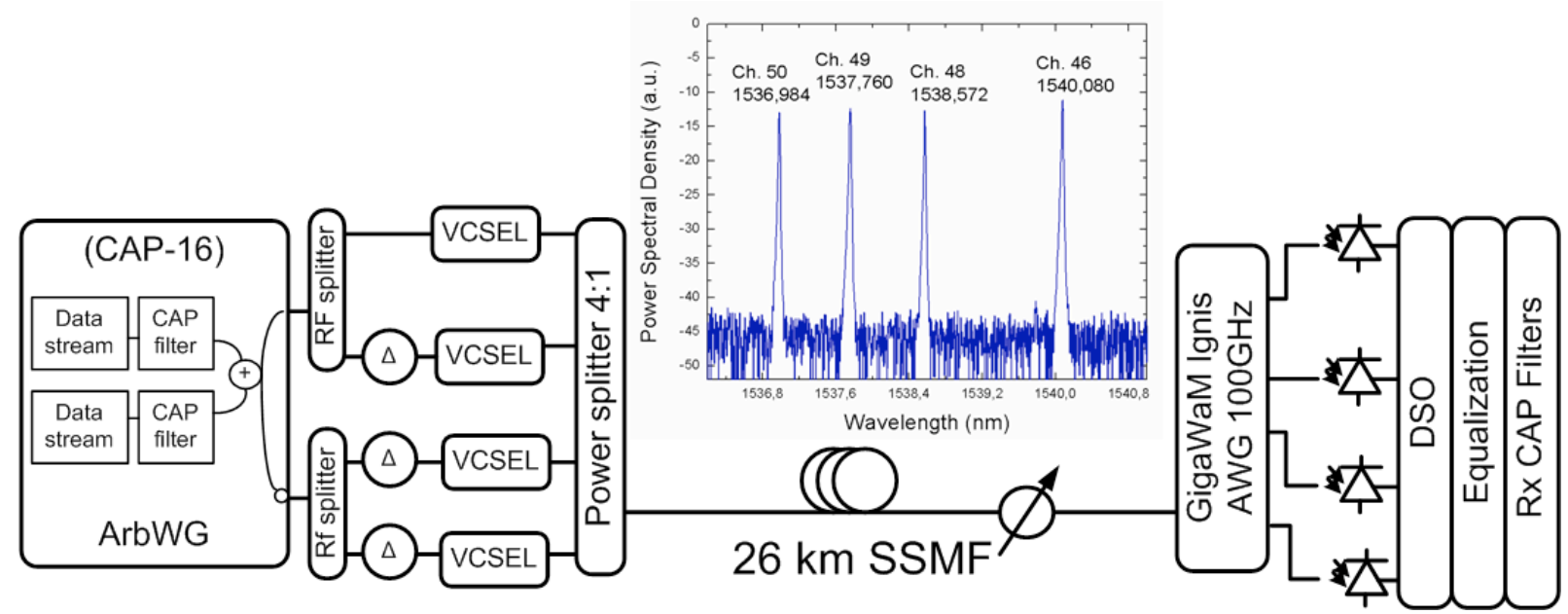

Fig. 1. Experimental Setup. Arbitrary waveform generator (ArbWG), array waveguide grating (AWG), digital storage scope (DSO).

\section{Results}

The VCSELs were tuned to fit the ITU channels number 50, 49, 48, and 46. The embedded graph in Fig. 1 shows the optical spectrum of the WDM-CAP signal with the corresponding wavelengths of each channel.

Figure 2 shows the CAP filters in time and frequency domain, and the electrical spectrum of the CAP signal directly from the ArbWG. The 3dB-bandwidth of each 1.25 Gbps CAP-16 is $312.5 \mathrm{MHz}$ that corresponds to $4 \mathrm{bit} / \mathrm{s} / \mathrm{Hz}$ spectral efficiency.
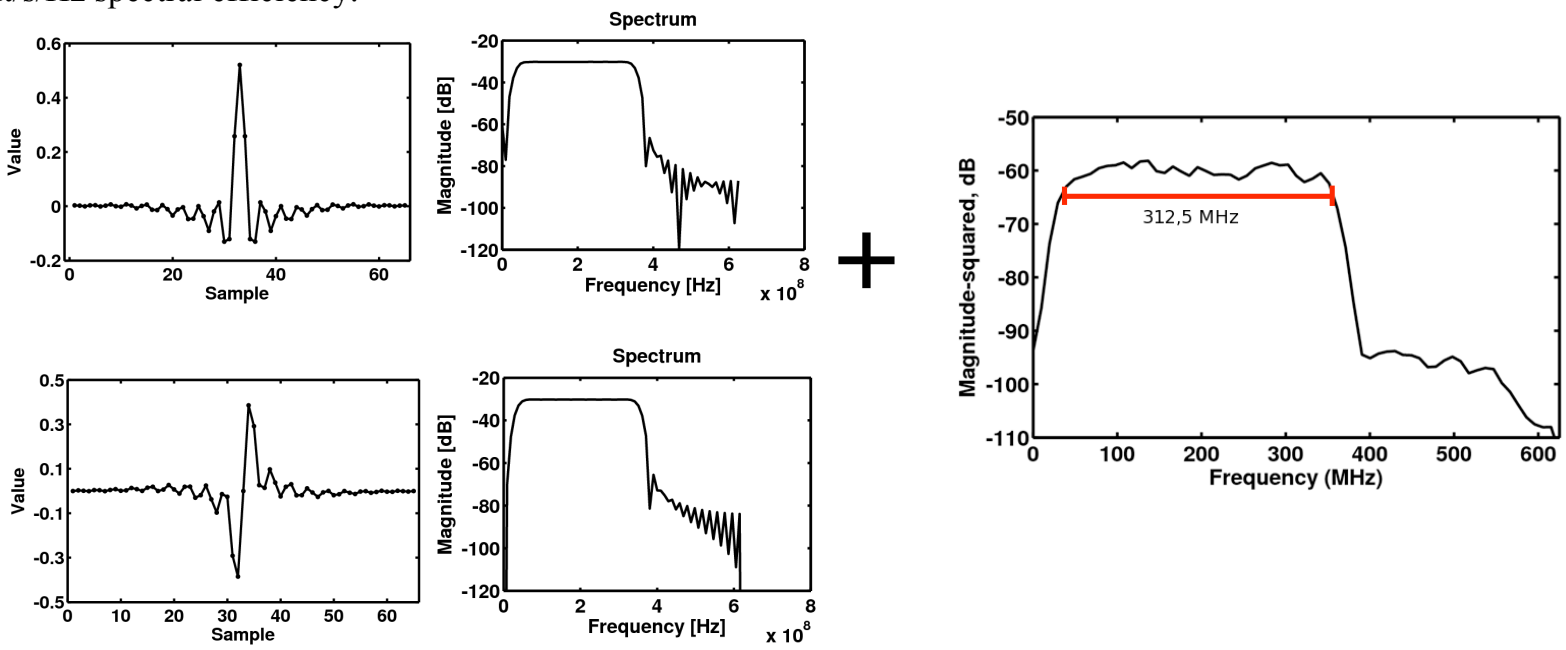

Fig. 2. CAP filters in time and frequency domain, and frequency spectrum of 1.25 Gbps CAP-16 after ArbWG

The received signal filtered with the receiver CAP filters is decomposed in both orthogonal components. Both components can be represented in an I/Q constellation diagram like QAM signals. Fig. 3.a shows the clear constellation diagram of the demodulated electrical B2B signal. Fig. 3.b shows the demodulated optical B2B with $-19 \mathrm{dBm}$ received optical power; constellation after electrical-to-optical conversion is still very clear. Fig. 3.c and d show the signals at $-22 \mathrm{dBm}$ received optical power, for $\mathrm{B} 2 \mathrm{~B}$ and after $26 \mathrm{~km}$ configurations, respectively. No constellation degradation is appreciated after transmission compared to $\mathrm{B} 2 \mathrm{~B}$, as it is shown also later in the BER curves. 

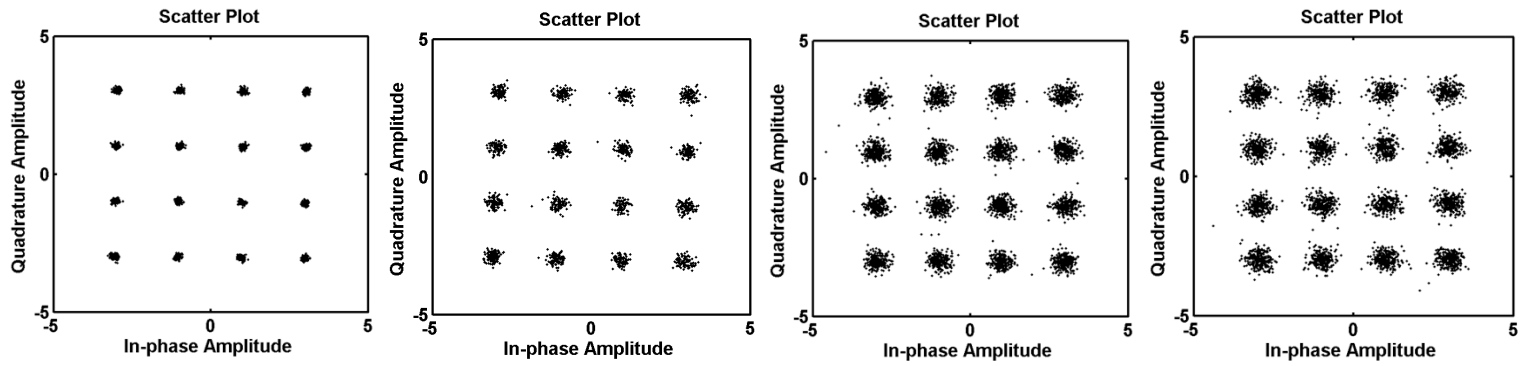

Fig. 3. Constellation CAP-16 for a) electrical B2B, b) optical B2B at $-19 \mathrm{dBm}$, c) optical B2B at -22 dBm. d) after $26 \mathrm{~km} \mathrm{SSMF} \mathrm{at} \mathrm{-22} \mathrm{dBm.}$

Figure 4.a shows the BER curves of the demodulated channel 49 to evaluate the transmission effects and cross talk between channels. The figure compares the performance when only channel 49 is transmitting and when the 4 channels are transmitting simultaneously. No receiver sensitivity power penalty is measured from multiplexing or transmission. Figure $4 . \mathrm{b}$ shows all 4 channels after $26 \mathrm{~km}$ transmission. The forward error correction (FEC) limit of $\mathrm{BER}=2,2 \cdot 10^{-3}$ is considered as a reference. We achieved received power sensitivity below $-24 \mathrm{dBm}$ for all the channels.
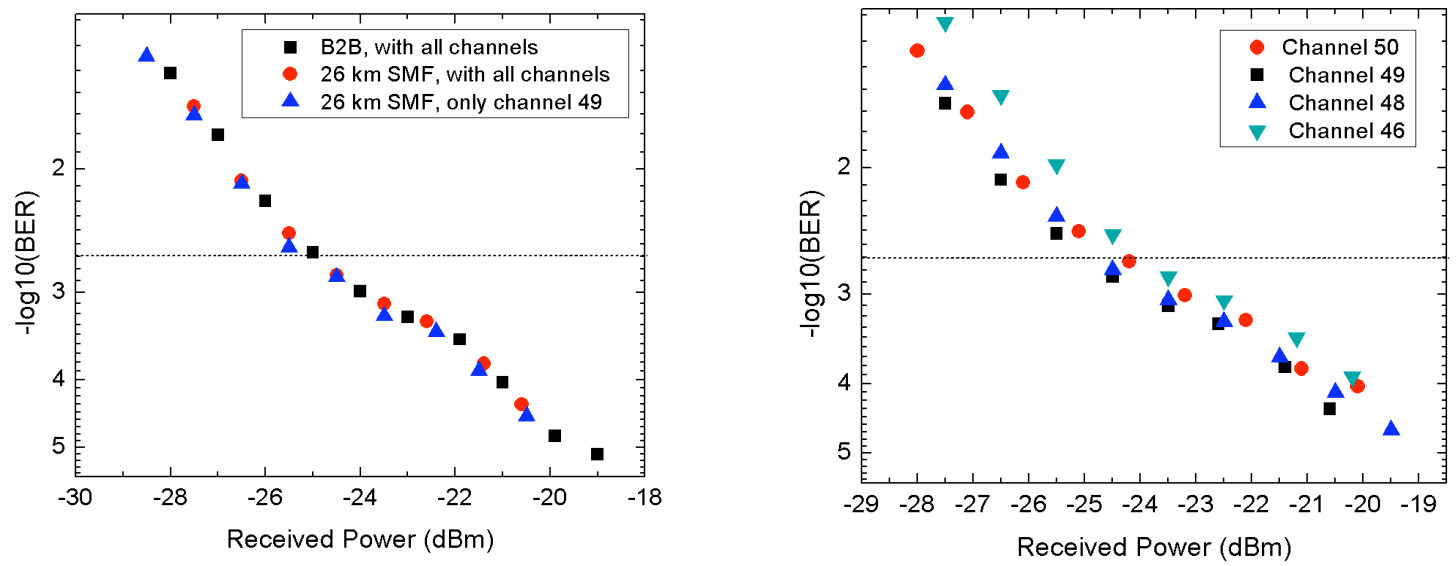

Fig. 4. BER curves CAP-16. a) Channel 49 b) all channels after $26 \mathrm{~km} \mathrm{SSMF.}$

\section{Summary}

We have experimentally demonstrated directly modulation of CAP-16 in commercially available VCSELs, with a spectral efficiency of $4 \mathrm{bit} / \mathrm{s} / \mathrm{Hz}$. The system has been evaluated with 4 close spaced channels at $1.25 \mathrm{Gbps}$ each, for a total bitrate of $5 \mathrm{Gbps}$ over $26 \mathrm{~km}$ fiber transmission. All the channels achieved received power sensitivity below $-24 \mathrm{dBm}$. Future work will evaluate the system for higher bitrates overcoming the transmitter limitations by using analog CAP filters.

We believe direct CAP modulation of VCSELs is a candidate for next generation PONs and short range systems due to the high spectral efficiency, scalability to higher order modulation, potentially low cost implementation and simplicity compare to modulation formats with carrier.

\section{References}

[1] I. Kalet, "The multitone channel," IEEE Trans. Commun., vol. 37, (Feb. 1989), pp.119-124.

[2] G.-H. Im, D. D. Harman, G. Huang, A. V. Mandzik, M.-H. Nguyen, and J.-J. Werner, "51.84 Mb/s 16-CAP ATM LAN standard," IEEE J. Select. Areas Commun., vol. 13 (1995), pp. 620-632.

[3] A. Shalash, K.K. Parhi, "Comparison of discrete multitone and carrierless AM/PM techniques for line equalization," IEEE International Symposium on Circuits and Systems, vol.2 (1996). pp. 560-563.

[4] J. D. Ingham, R. Penty, I. White, D. Cunningham. "40 Gb/s Carrierless Amplitude and Phase Modulation for Low-Cost Optical Datacommunication Links," Conference on Optical Fiber Communications, OFC (2011).

[5] Chen, W. Y.; Im, G. H.; Werner, J. J.; , "Design of Digital Carrierless AM/PM Transceivers", AT\&T and Bellcore contribution to ANSI T1E1.4/92-149, (1992)

[6] M. Wieckowski, J. B. Jensen, I. Tafur Monroy, J. Siuzdak, J. P. Turkiewicz. " 300 Mbps Transmission with 4.6 bit/s/Hz Spectral Efficiency over 50 m PMMA POF Link Using RC-LED and Multi-Level Carrierless Amplitude Phase Modulation," Conference on Optical Fiber Communications, OFC (2011).

[7] A. Shalash, K.K. Parhi, " Multidimensional Carrierless AM/PM Systems for Digital Subscriber Loops," IEEE Transactions on Communications, vol. 47, no. 11, November (1999). 